OPEN ACCESS

Edited by:

Eytan Wine,

University of Alberta, Canada

Reviewed by:

Amit Assa,

Schneider Children's Hospital,

United States

Tudor Lucian Pop,

Iuliu Hatieganu University of Medicine

and Pharmacy, Romania

*Correspondence:

Christine Sempoux

christine.sempoux@chuv.ch

Specialty section

This article was submitted to Pediatric Gastroenterology

Hepatology and Nutrition,

a section of the journal

Frontiers in Pediatrics

Received: 16 January 2018 Accepted: 13 April 2018

Published: 01 May 2018

Citation:

Saglietti C, Sciarra A, Abdelrahman K, Schneider V, Karpate A, Nydegger A and Sempoux C (2018) Autoimmune

Gastritis in the Pediatric Age: An Underestimated Condition Report of

Two Cases and Review.

Front. Pediatr. 6:123.

doi: 10.3389/fped.2018.00123

\section{Autoimmune Gastritis in the Pediatric Age: An Underestimated Condition Report of Two Cases and Review}

\author{
Chiara Saglietti ${ }^{1}$, Amedeo Sciarra ${ }^{1}$, Karim Abdelrahman ${ }^{2}$, Vanessa Schneider ${ }^{1}$, \\ Arti Karpate ${ }^{1}$, Andreas Nydegger ${ }^{3}$ and Christine Sempoux ${ }^{1 *}$ \\ ${ }^{1}$ Institute of Pathology, Lausanne University Hospital, Lausanne, Switzerland, ${ }^{2}$ Gastroenterology and Hepatology \\ Department, Lausanne University Hospital, Lausanne, Switzerland, ${ }^{3}$ Pediatric Gastroenterology Unit, Department of \\ Pediatrics, Lausanne University Hospital, Lausanne, Switzerland
}

Background: Diagnosis of pediatric autoimmune gastritis (AIG) in children is important due to poor outcome and risk of malignancy. This condition is often underestimated in the clinico-pathologic diagnostic work-up, leading to delayed time-to-diagnosis. To increase the awareness of this condition in the pediatric population, we present two cases encountered at our institution, discuss their clinical, biological, and histological presentations in relation with evidence from the literature, and propose an algorithm for diagnosis and follow-up of AIG in children.

Case presentation: Two patients (12 and 17 years old) presented with iron deficiency anemia and negative family history for autoimmune disorders. In both cases, the final diagnosis of autoimmune gastritis was delayed until pathological examination of endoscopic gastric biopsies showed atrophy of oxyntic glands. Helicobacter pylori search was negative. Follow up biopsies revealed persistent disease. Literature review on this condition shows unclear etiology and poor long term outcome in some patients because of increased risk of malignancy.

Conclusions: AIG should be considered in the differential diagnosis of iron deficiency anemia in the pediatric population.Standardized clinico-pathologic work-up is mandatory. Endoscopic follow-up should be performed due to the risk of malignancy.

Keywords: autoimmune gastritis, gastric atrophy, children, intestinal metaplasia, ECL cell hyperplasia, irondeficiency anemia

\section{BACKGROUND}

Autoimmune gastritis (AIG) is a chronic progressive inflammatory condition that is characterized by destruction of oxyntic glands and their replacement by atrophic and metaplastic mucosa, typically accompanied by lymphoplasmacytic infiltration of the lamina propria. The decrease or disappearance of parietal cells results in hypochlorhydria or achlorhydria and loss of intrinsic factor, which interfere with intestinal absorption of iron and vitamin $B_{12}$, respectively (1). Iron and vitamin $\mathrm{B}_{12}$ malabsorption is responsible for a spectrum of clinical signs and laboratory

Abbreviations: AIG, autoimmune gastritis; IDA, iron-deficiency anemia; ECL, enterochromaffin-like 
alterations, including iron-deficiency (IDA), and megaloblastic anemia. Moreover, increased gastric $\mathrm{pH}$ relieves somatostatinmediated inhibition of antral gastrin-producing cells, and the ensuing hypergastrinemia induces proliferation of enterochromaffin-like (ECL) cells, which may give rise to neuroendocrine tumors (2-4).

Although it has traditionally been considered as a disease predominantly affecting elderly women of Northern European descent, recent clinical reports have described this condition in pediatric patients, especially in association with refractory iron-deficiency anemia and other autoimmune diseases (5-14).

\section{CASE PRESENTATION}

\section{Case 1}

A 12-year-old girl with a history of paleness, epigastric pain and menorrhagia, and no previous personal or family history of autoimmune disease, was referred to our hospital to evaluate a microcytic hypochromic anemia $(\mathrm{Hb}=10.6 \mathrm{~g} / \mathrm{dl} ; \mathrm{MCV}=64$ $\mathrm{fl} ; \mathrm{MCH}=19.4 \mathrm{pg} ; \mathrm{MCHC}=302 \mathrm{~g} / \mathrm{l} ;$ iron $=2.7 \mu \mathrm{mol} / \mathrm{l}$; ferritin $=6 \mu \mathrm{g} / \mathrm{l}$ ) unresponsive to oral iron treatment. Because of positive fecal occult blood test and elevated fecal calprotectin $(705 \mu \mathrm{g} / \mathrm{g})$, she underwent upper and lower endoscopy, to look for sources of gastrointestinal bleeding. Colonoscopy and histological examination of colonic biopsies taken during the procedure were unremarkable. Upper endoscopy imaging was also unremarkable, but the histological examination revealed chronic atrophic gastritis at both fundic and antral level.

Specifically, fundic biopsies showed a complete atrophy of the oxyntic glands and intestinal metaplasia, accompanied by a moderate inflammatory infiltrate composed of lymphocytes, plasma cells, eosinophils, and rare neutrophils. Linear and micronodular hyperplasia of ECL cells was demonstrated with immunohistochemical staining for chromogranin A. Antral biopsies exhibited a moderate chronic atrophic gastritis, without inflammatory activity and intestinal metaplasia. Helicobacter pylori search was negative after Giemsa-stained special coloration and immunohistochemical staining with anti-Helicobacter pylori specific antibody. A representative picture of these histological findings is shown in Figure 1.

Fecal H. pylori antigen test was positive, and the patient received a triple therapy with amoxicillin, clarithromycin for 14 days and esomeprazole for 1 month. Subsequent fecal antigen negative test confirmed $H$. pylori eradication. However, in a follow-up upper endoscopy performed 15 months later, histological examination proved unmodified. AIG was confirmed after further laboratory investigations revealing the presence of anti-parietal cell antibodies (1/1280 titer). Anti-intrinsic factor antibodies were negative and vitamin $\mathrm{B}_{12}$ levels were normal (164 pmol/l). Serum gastrin level was not assessed, as the patient was on esomeprazole, and urinary methylmalonic acid and homocysteine levels were not tested.

\section{Case 2}

A 17-year-old girl with a history of menorrhagia, fatigue and dizziness, and no previous personal or family history of autoimmune disease, was referred to our hospital to evaluate an IDA $(\mathrm{Hb}=6.7 \mathrm{~g} / \mathrm{dl} ; \mathrm{MCV}=56 \mathrm{fl} ; \mathrm{MCH}=16.1 \mathrm{pg}$; $\mathrm{MCHC}=288 \mathrm{~g} / \mathrm{l}$; iron $=8.1 \mu \mathrm{mol} / \mathrm{l}$ ) unresponsive to oral iron supplementation. Again, colonoscopy and upper endoscopy were unremarkable, but histological examination of gastric biopsies revealed chronic atrophic gastritis.

Specifically, fundic biopsies showed complete atrophy of the oxyntic glands, with pseudo-pyloric metaplasia, accompanied by a mild inflammatory infiltrate composed of lymphocytes and plasma cells; micronodular hyperplasia of ECL cells was demonstrated with immunohistochemical staining for chromogranin A. H. pylori search was negative after Giemsa-stained special coloration and immunohistochemical staining with Anti-Helicobacter pylori specific antibody. Only

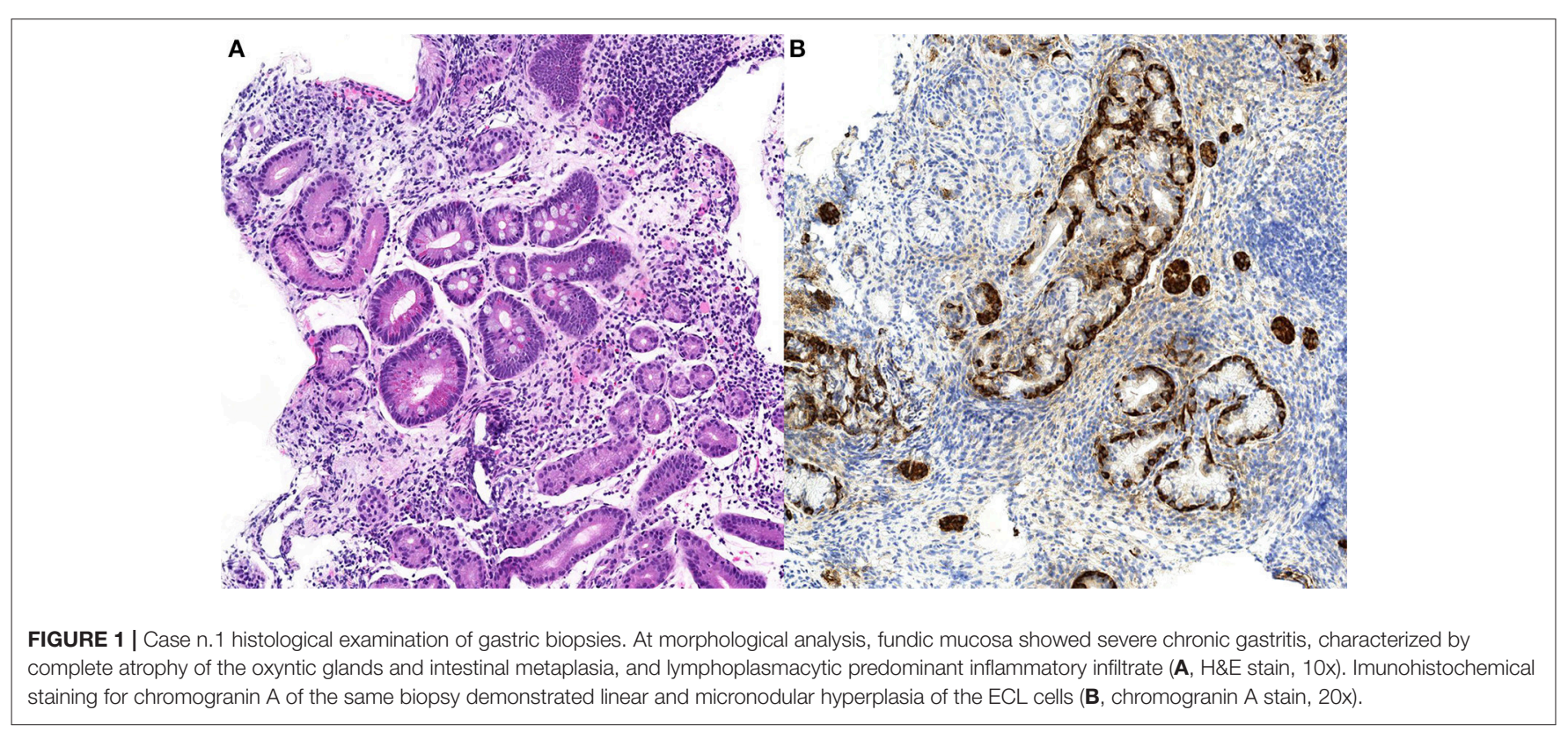




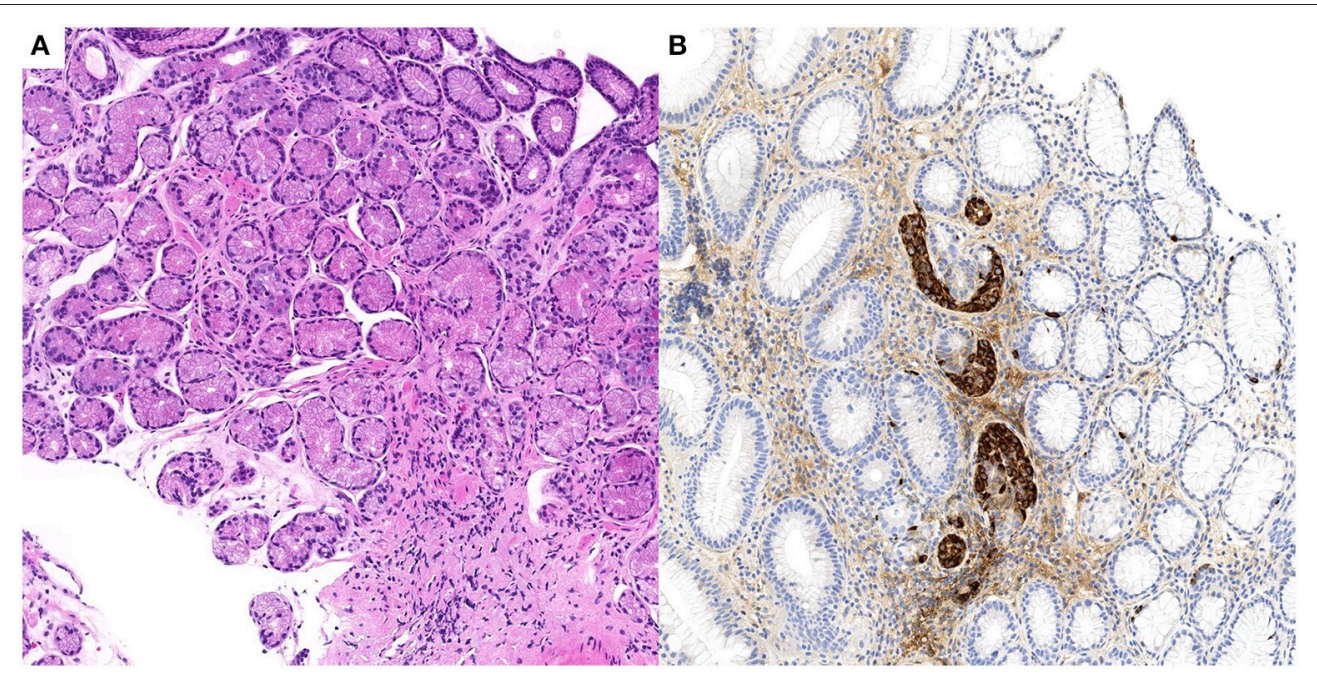

FIGURE 2 | Case n.2 histological examination of gastric biopsies. At morphological analysis, fundic mucosa showed mild chronic gastritis, characterized by complete atrophy of the oxyntic glands and pseudopyloric metaplasia (A, H\&E stain, 10x). Imunohistochemical staining for chromogranin A of the same biopsy demonstrated linear and micronodular ECL cell hyperplasia (B, chromogranin A stain, 10x).

mild chronic inflammation was observed in the antrum. A representative picture of these histological findings is shown in Figure 2.

After 7 months, a follow-up upper endoscopy histological examination demonstrated persisting fundic chronic atrophic gastritis with linear and micronodular hyperplasia of ECL. AIG was confirmed after further laboratory investigations revealing the presence of anti-parietal cell antibodies (1/2560 titer). Anti-intrinsic factor antibodies, as well as celiac disease or autoimmune thyroiditis specific serological tests, were negative. Vitamin B12 levels were normal (257 pmol/l). Urinary methylmalonic acid and homocysteine levels were not tested.

\section{DISCUSSION AND CONCLUSIONS}

In the cases reported here, AIG was a late and unexpected discovery in the diagnostic workup of a refractory anemia. This is in accordance with other previously published pediatric cases (Table 1), for which upper endoscopy was often delayed, in the context of refractory IDA, epigastric pain, or in the follow-up of other autoimmune diseases $(6,9,11-16)$.

When considering the whole of all pediatric patients reported in the literature, the average age at the diagnosis was 12.3 years, ranging from 8 months to 18 years. The most common presentations were refractory or recurrent IDA, followed by non-specific gastrointestinal symptoms. To further complicate the diagnosis, reported endoscopic findings were non-specific in most cases, and coexistence of positive anti-gastric parietal cells antibodies, vitamin B12 deficiency, and hypergastrinemia were present only in a minority of patients. Therefore, as in our cases, histologic examination was often the first analysis suggesting the possibility of AIG (9). It should be stressed that AIG is, by definition, a pathological process of the gastric body. Therefore, in the routine diagnostic workup of IDA, the clinician should always submit endoscopic biopsies from the gastric body and from the gastric antrum separately for pathological analysis. In the absence of fundic lesions, atrophia, and metaplastic changes occurring in the antrum are not a sign of AIG. Furthermore, fundic origin of the submitted biopsies has to be correctly identified by pathologists and special attention has to be paid not to misinterpret complete fundic atrophia as an antral specimen. For this specific purpose, a negative gastrin immunohistochemical staining can help to confirm the fundic origin of the samples. H. pylori infection, which is, to the best of our knowledge, the only differential diagnosis to consider should be attentively investigated, clinically, and pathologically.

As far as hematological alterations are concerned, pernicious anemia is not the only manifestation associated with AIG: by stratifying patients with AIG according to age, Hershko et al. suggested that IDA is the most frequent hematological presentation in young patients, and that there is a progressive increase in mean corpuscular volume and severity of vitamin $\mathrm{B}_{12}$ deficiency with advancing age at presentation (5). Young patients presenting with microcytic anemia are almost exclusively women, thus implying that menstrual blood loss may have a role in the development of iron deficiency, aggravated by the inability to increase food iron absorption due to hypochlorhydria. In effect, both of our patients had a history of menorrhagia, which could have contributed to their anemia (5).

The study of Hershko et al. has also shown a high prevalence of $H$. pylori positivity in young patients with AIG and microcytic anemia. Although the most common trigger of AIG in adults is $H$. pylori infection, with mechanisms of molecular mimicry hypothesized as initiating event of gastric autoimmunity on the basis of cross-reaction between $H$. pylori antigens and gastric $\mathrm{H}^{+}, \mathrm{K}^{+}$-ATPase, AIG appears to be a late complication of infection, as any ECL cell hyperplasia that may arise in that context (17). Therefore, the role of $H$. pylori 


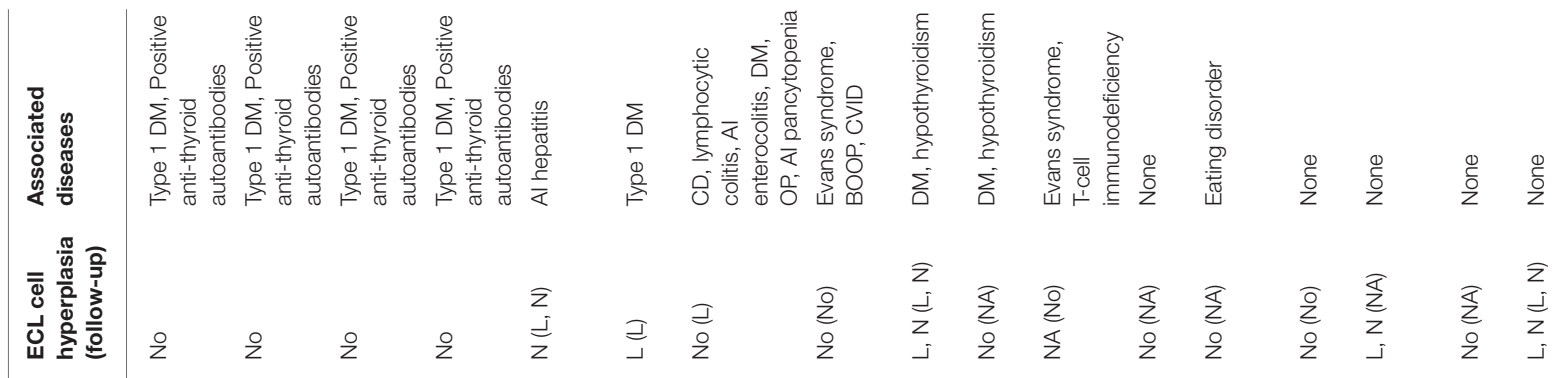

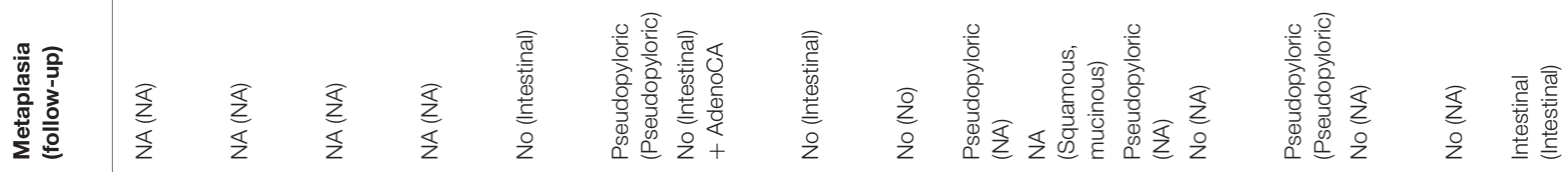

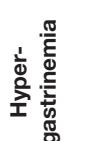

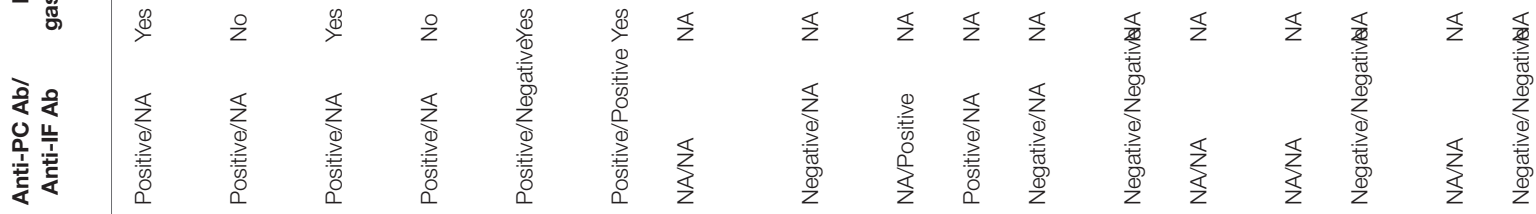

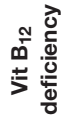

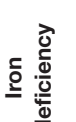

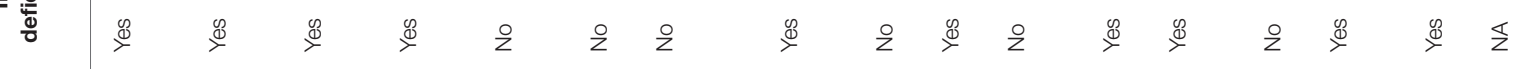

爱

空总高

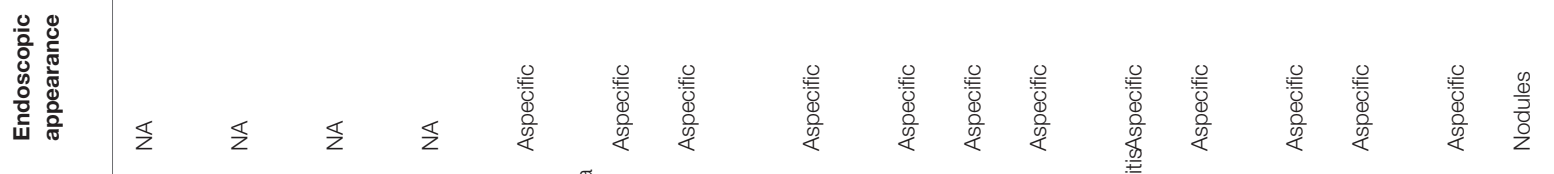

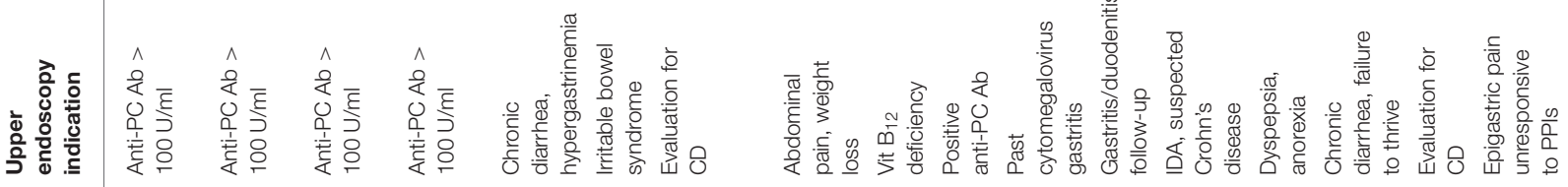

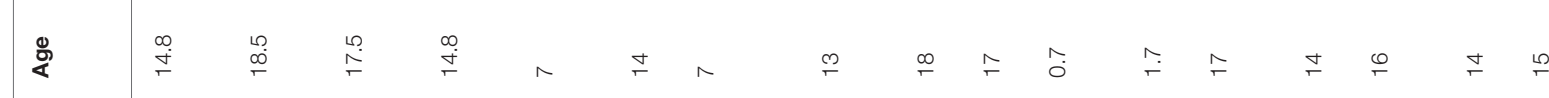

음

.

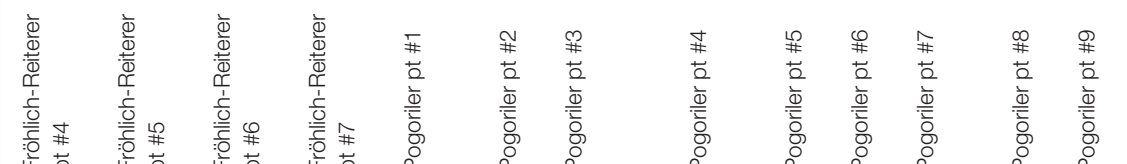

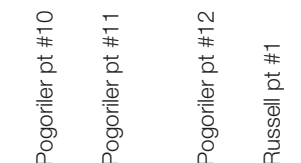




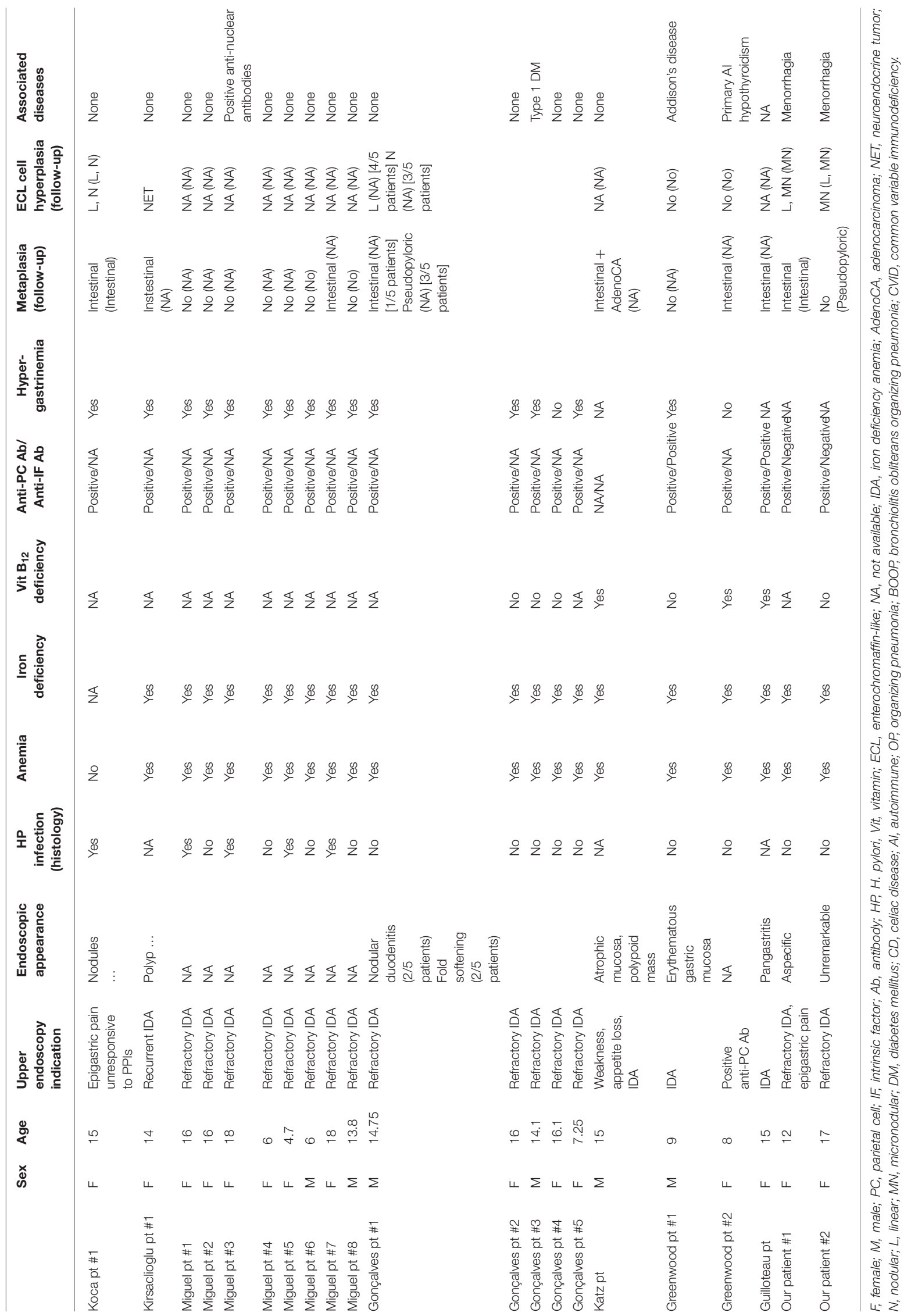




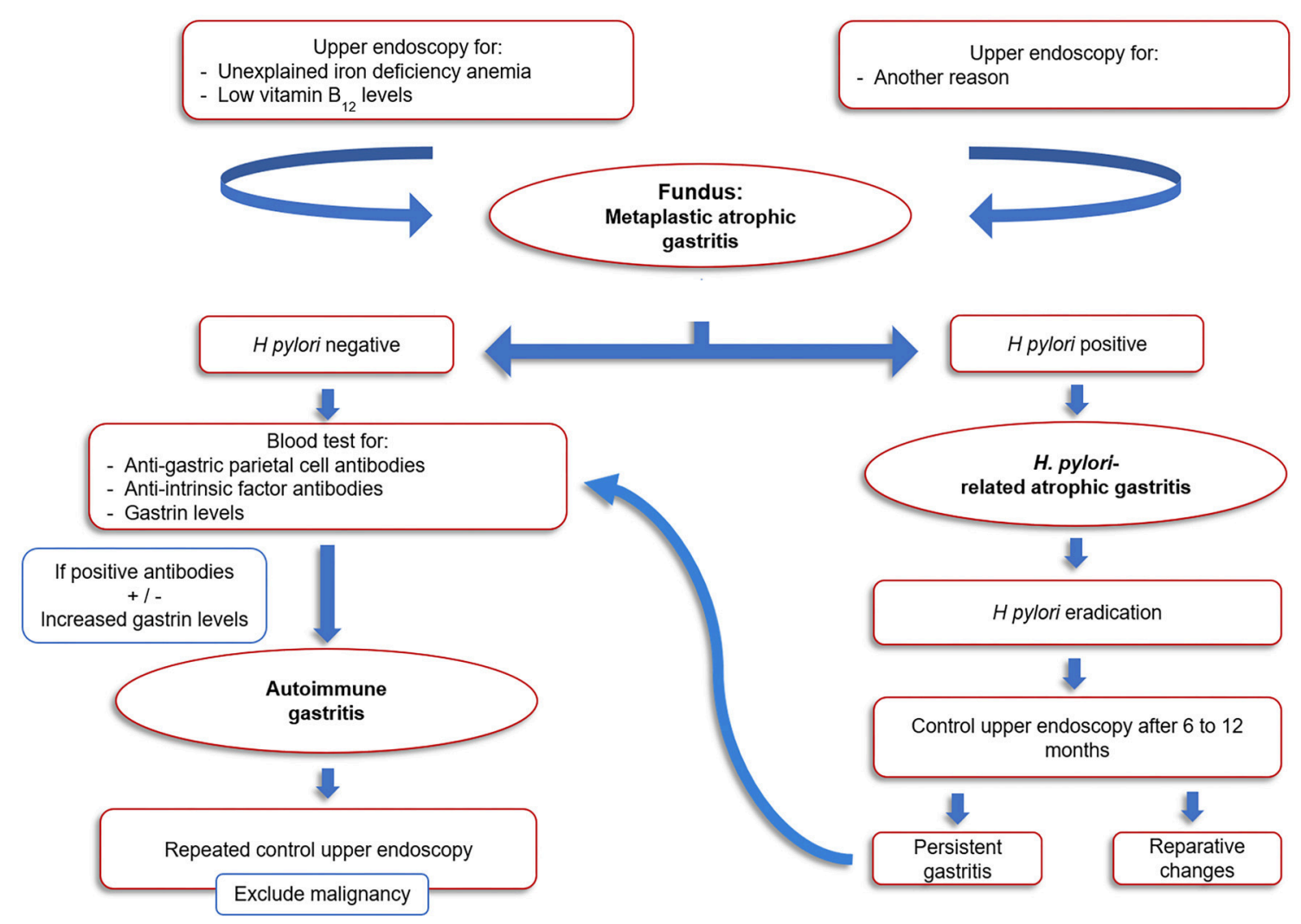

FIGURE 3 | Algorithm suggested for the diagnosis and follow-up of pediatric autoimmune gastritis.

infection in pathogenesis of AIG in pediatric population remains controversial. Although some authors have described remission of autoimmune atrophic gastritis after eradication of $H$. pylori infection in adults, we did not observe any improvement in gastric atrophy of our first patient after eradication therapy (18). The same observation was made by other authors who followedup pediatric patients with $H$. pylori infection and $\operatorname{AIG}(9,10)$. However, as $H$. pylori eradication is a simple procedure most of the times, regular search and treatment in case of positivity are recommended (8).

The long-term outcome of AIG in children has not been investigated yet. Our findings, in line with those of other authors, have shown no improvement in gastric atrophy, metaplasia, or ECL cell hyperplasia over time, consistently with known progression of AIG in adult patients $(3,4,8,10)$.

AIG is associated with intestinal-type gastric cancer and type I neuroendocrine tumors $(3,4)$. Consequently, it deserves particular attention as a preneoplastic condition in children, considering their long life expectancy. Different pathophysiological mechanisms are involved in the development of such gastric tumors: a pathological sequence of events progressing through inflammation, metaplasia and dysplasia ultimately results in intestinal-type gastric adenocarcinoma;(1) gastrin acts as a growth factor for ECL cells, and hypergastrinemia caused by achlorhydria induces ECL cell proliferations, which can develop into neuroendocrine tumor. In addition, ECL cells produce histamine, basic fibroblast growth factor and Reg protein, which are well-established to have trophic effects; therefore, it is reasonable to hypothesize that neuroendocrine cells play a role also in the pathogenesis of gastric cancer of the intestinal type (2). In published reports about neoplastic evolution of gastric atrophy in the pediatric population, one patient developed gastric adenocarcinoma at the age of 17 years, 8 years after initial diagnosis of AIG;(9) one patient developed a poorly differentiated gastric adenocarcinoma at 17 years, two and a half year after initial diagnosis;(11) a further patient presented at first upper endoscopy with a gastric neuroendocrine tumor in a background of autoimmune atrophic gastritis at the age of 14 (7).

Since no curative therapy is available for AIG, treatment of this condition is focused on preventing vitamin B12 and iron deficiencies. Since dietary and oral iron supplements do not usually improve iron levels, alternative iron therapy approaches such as intravenous iron oral supplementation of ferrous glycine sulfate can be proposed (19). To date, the endoscopic follow up of AIG is still matter of debate and no specific guidelines for the pediatric population are available. For the adult population, the American Society for Gastrointestinal Endoscopy recommended in 2006 a single endoscopic evaluation for neoplastic lesions after diagnosis of AIG but no routine follow-up, while the guidelines from the European Society of Gastrointestinal Endoscopy recommends that once the 
diagnosis of AIG is established, follow-up endoscopies should be performed every 3 years to screen for the development of gastric malignancies $(20,21)$. Due to the longer life expectancy of the pediatric population and considering the relatively high risk of malignant transformation, surveillance protocols should be put in place for these patients. An algorithm for the diagnosis and follow-up of pediatric AIG is suggested in Figure 3.

In conclusion, physicians and pathologists should be aware of AIG existence also in the pediatric population. The histopathological examination can shorten the diagnostic delay, provided that adequate sampling of the stomach with body and antrum biopsies sent separately is performed. Poor outcome and risk of malignancy should be considered in the management strategy of these patients, taking into account their long life expectancy.

\section{REFERENCES}

1. Neumann WL, Coss E, Rugge M, Genta RM. Autoimmune atrophic gastritispathogenesis, pathology and management. Nat Rev Gastroenterol Hepatol. (2013) 10:529-41. doi: 10.1038/nrgastro.2013.101

2. Waldum HL, Hauso $\varnothing$, Fossmark R. The regulation of gastric acid secretion - clinical perspectives. Acta Physiol. (2014) 210:239-56. doi: 10.1111/apha.12208

3. La Rosa S, Vanoli A, Gastric neuroendocrine neoplasms and related precursor lesions. J Clin Pathol. (2014) 67:938-48. doi: 10.1136/jclinpath-2014202515

4. Vanoli A, La Rosa S, Luinetti O, Klersy C, Manca R, Alvisi C, et al. Histologic changes in type A chronic atrophic gastritis indicating increased risk of neuroendocrine tumor development: the predictive role of dysplastic and severely hyperplastic enterochromaffin-like cell lesions. Hum Pathol. (2013) 44:1827-37. doi: 10.1016/j.humpath.2013.02.005

5. Hershko C, Ronson A, Souroujon M, Maschler I, Heyd J, Patz J. Variable hematologic presentation of autoimmune gastritis: age-related progression from iron deficiency to cobalamin depletion. Blood (2006) 107:1673-9. doi: 10.1182/blood-2005-09-3534

6. Russell AC, Black JO, Schwartz DA, Correa H, Rosen MJ. 15-yearold girl with metaplastic atrophic gastritis and enterochromaffin-like cell hyperplasia. J Pediatr Gastroenterol Nutr. (2012) 55:e148-51. doi: 10.1097/MPG.0b013e318242da36

7. Kirsaclioglu CT, Kuloglu Z, Kansu A, Ensari A, Siklar Z, Berberoglu M, et al. Gastric carcinoid tumor in a 14-year old girl. Scand J Gastroenterol. (2014) 49:1391-3. doi: 10.3109/00365521.2014.953574

8. Miguel N, Costa E, Santalha M, Lima R, Vizcaino JR, Pereira, F et al. Refractory iron-deficiency anemia and autoimmune atrophic gastritis in pediatric age group: analysis of 8 clinical cases. J Pediatr Hematol Oncol. (2014) 36:134-9. doi: 10.1097/MPH.0000000000000069

9. Pogoriler J, Kamin D, Goldsmith JD. Pediatric non-Helicobacter pylori atrophic gastritis: a case series. Am J Surg Pathol. (2015) 39:786-92. doi: 10.1097/PAS.0000000000000378

10. Koca T, Dereci S, Karahan N, Akcam M. Gastrointestinal neuroendocrine tumors in two children. Indian Pediatr. (2016) 53:70-2. doi: 10.1007/s13312-016-0924-y

11. Katz S, Berernheim J, Kaufman Z, Lazar L, Erez I, Wolach B. Pernicious anemia and adenocarcinoma of the stomach in an adolescent: clinical presentation and histopathology. J Pediatr Surg. (1997) 32:1384-5. doi: 10.1016/S0022-3468(97)90330-4

12. Guilloteau M, Bertrand Y, Lachaux A, Mialou V, Le Gall C, Girard S. [Pernicious anemia: a teenager with an unusual cause of irondeficiency anemia]. Gastroenterol Clin Biol. (2007) 31:1155-6. doi: 10.1016/S0399-8320(07)78357-4

13. Greenwood DL, Crock P, Braye S, Davidson P, Sentry JW. Autoimmune gastritis and parietal cell reactivity in two children with

\section{ETHICS STATEMENT}

Samples were used in accordance with the Declaration of Helsinki. Written informed consent for publication of the case report was obtained from the patient or from the patient's parent/guardian, in the case of a minor.

\section{AUTHOR CONTRIBUTIONS}

CS, AS, AN, and CSX: Study design, data collection, drafting. KA, VS, and AK: Data collection.

\section{ACKNOWLEDGMENTS}

Authors thank Prof. Jacopo Saturno (linguistics department, University of Milan) for reviewing the text.

abnormal intestinal permeability. Eur J Pediatr. (2008) 167:917-25. doi: 10.1007/s00431-007-0664-Z

14. Goncalves C, Oliveira ME, Palha AM, Ferrao A, Morais A, Lopes AI. Autoimmune gastritis presenting as iron deficiency anemia in childhood. World J Gastroenterol. (2014) 20:15780-6. doi: 10.3748/wjg.v20.i42.15780

15. Frohlich-Reiterer EE, Huber J, Katz H, Suppan E, Obermayer-Pietsch B, Deutschmann A, et al. Do children and adolescents with type 1 diabetes mellitus have a higher frequency of parietal cell antibodies than healthy controls? J Pediatr Gastroenterol Nutr. (2011) 52:558-62. doi: 10.1097/MPG.0b013e3181fedb2a

16. Segni M, Borrelli O, Pucarelli I, Delle Fave G, Pasquino AM, Annibale B. Early manifestations of gastric autoimmunity in patients with juvenile autoimmune thyroid diseases. J Clin Endocrinol Metab. (2004) 89:4944-8. doi: 10.1210/jc.2003-031597

17. Amedei A, Bergman MP, Appelmelk BJ, Azzurri A, Benagiano M, Tamburini $\mathrm{C}$, et al. Molecular mimicry between Helicobacter pylori antigens and $\mathrm{H}+, \mathrm{K}+$ -adenosine triphosphatase in human gastric autoimmunity. J Exp Med. (2003) 198:1147-56. doi: 10.1084/jem.20030530

18. Ito M, Haruma K, Kamada T, Mihara M, Kim S, Kitadai Y, et al. Helicobacter pylori eradication therapy improves atrophic gastritis and intestinal metaplasia: a 5-year prospective study of patients with atrophic gastritis. Aliment Pharmacol Ther. (2002) 16:1449-56. doi: 10.1046/j.1365-2036.2002.01311.x

19. Kulnigg-Dabsch S. Autoimmune gastritis. Wien Med Wochenschrift 1946 (2016) 166:424-30. doi: 10.1007/s10354-016-0515-5

20. Hirota WK, Zuckerman MJ, Adler DG, Davila RE, Egan J, Leighton JA, et al. ASGE guideline: the role of endoscopy in the surveillance of premalignant conditions of the upper GI tract. Gastrointest Endosc. (2006) 63:570-80. doi: 10.1016/j.gie.2006.02.004

21. Dinis-Ribeiro M, Areia M, de Vries AC, Marcos-Pinto R, Monteiro-Soares $\mathrm{M}$, O'Connor A, et al. Management of precancerous conditions and lesions in the stomach (MAPS): guideline from the European Society of Gastrointestinal Endoscopy (ESGE), European Helicobacter Study Group (EHSG), European Society of Pathology (ESP), and the Sociedade Portuguesa de Endoscopia Digestiva (SPED). Endoscopy (2012) 44:74-94. doi: 10.1055/s-0031-1291491

Conflict of Interest Statement: The authors declare that the research was conducted in the absence of any commercial or financial relationships that could be construed as a potential conflict of interest.

Copyright (c) 2018 Saglietti, Sciarra, Abdelrahman, Schneider, Karpate, Nydegger and Sempoux. This is an open-access article distributed under the terms of the Creative Commons Attribution License (CC BY). The use, distribution or reproduction in other forums is permitted, provided the original author(s) and the copyright owner are credited and that the original publication in this journal is cited, in accordance with accepted academic practice. No use, distribution or reproduction is permitted which does not comply with these terms. 